\title{
Effect of Radiation on Diesel Engine Combustion and Heat Transfer*
}

\author{
Takeshi YOSHIKAWA** and Rolf D. REITZ** \\ **Engine Research Center, Department of Mechanical Engineering \\ University of Wisconsin-Madison \\ 1500 Engineering Dr., Madison, Wisconsin 53705, U.S.A. \\ E-mail:yoshikawa@wisc.edu, reitz@engr.wisc.edu
}

\begin{abstract}
An investigation of the effect of radiation on $\mathrm{NO}_{\mathrm{x}}$ emission was conducted for low temperature diesel engine combustion by using advanced numerical models in a Computational Fluid Dynamics code. The Discrete Ordinates Method (DOM) model was used for the prediction of radiation, which is mainly radiated from soot emissions. The advanced numerical model was able to predict the pressure and heat release rate for a wide range of Start Of Injection (SOI) timing cases. It was found that the influence of the radiation was larger on soot formation than on $\mathrm{NO}_{\mathrm{x}}$ formation. However, the influence of the radiation on the emissions was smaller than the influence of the wall temperature on emissions. The reaction-induced interaction between $\mathrm{NO}_{\mathrm{x}}$ and soot emissions was found to be very small, only up to $2.5 \%$ difference of engine-out $\mathrm{NO}_{\mathrm{x}}$ concentration.
\end{abstract}

Key words: Heat Transfer, Thermal Radiation, $\mathrm{CFD}$, Soot, $\mathrm{NO}_{\mathrm{x}}$, Emissions

\section{Introduction}

The interest of the present investigations was to assess how radiation heat transfer which is mainly generated from soot formation affects the diesel combustion event and the production of pollutant emissions, and the role of combustion chamber wall surface temperatures. The relationship between soot and $\mathrm{NO}_{\mathrm{x}}$ emissions has been studied by many researchers who also considered the influences of chemistry and heat transfer. Guo et al. ${ }^{(1)}$ investigated the interaction of $\mathrm{NO}$ and soot formation in a laminar diffusion flame by numerical simulation, and reported that the formation of NO had little effect on the formation of soot. However, the formation of soot in the flame significantly suppressed the formation of $\mathrm{NO}$, such that the peak NO concentration and NO emissions were reduced by $28 \%$ and $46 \%$, respectively, due to the formation of soot by reaction- and thermal-induced effects. Musculus ${ }^{(2)}$ reported a "NO bump", which was manifested as an increase of $\mathrm{NO}_{\mathrm{x}}$ emissions when the combustion luminosity decreased in experiments conducted in the optical diesel engine of the Sandia National Laboratory. The influence of radiation cooling due to soot formation was predicted to reduce the flame temperature by $25-50 \mathrm{~K}$ for early Start Of Injection (SOI) timing, and to reduce $\mathrm{NO}_{\mathrm{x}}$ emissions by $12-25 \%$. In the present study the Sandia optical engine data was chosen to study the influence of soot and its radiation heat transfer on combustion and $\mathrm{NO}_{\mathrm{x}}$ emissions using advanced numerical models with the Computational Fluid Dynamics (CFD) code, KIVA-CHEMKIN.

Abraham $^{(3)}$ reported that radiation led to significant reduction of $\mathrm{NO}_{\mathrm{x}}$ emissions in an engine which had a 7.5 degree included fuel spray angle from the cylinder head by CFD. It suggested that formation of soot had effects on $\mathrm{NO}_{\mathrm{x}}$ emissions in terms of radiation and the piston wall also could have effects on emissions according to relatively narrow fuel spray 
angle from the cylinder head. In this paper the effects of the configuration of the fuel spray and the geometry of the piston bowl on the radiation heat loss and emissions are also investigated. For comparison with the model prediction, experimental results obtained by Genzale $^{(4)}$ were selected, where the spray angle, diameter and depth of the piston bowl, and the swirl ratio were changed. The engine used in the experiments was the same Sandia optical engine used by Musculus ${ }^{(2)}$.

\section{Nomenclature}

$\begin{array}{llll}a: & \text { absorption coefficient } & r: & \text { position vector } \\ C_{2}: & \text { the second Plank coefficient } & S: & \text { source term of intensity due to } \\ f_{v}: & \text { volumetric fraction of soot } & & \text { scattering } \\ I: & \text { radiation intensity } & V: & \text { volume } \\ I_{b}: & \text { intensity of blackbody radiation } & T_{\text {soot }}: & \text { soot temperature } \\ I_{w}: & \text { radiation intensity leaving wall } & \varepsilon: & \text { surface emissivity } \\ k: & \text { non-dimensional absorption } & \rho: & \text { surface reflectivity } \\ & \text { coefficient } & \sigma_{s}: & \text { scattering coefficient } \\ L: & \text { thickness of soot cloud } & \phi: & \text { equivalence ratio } \\ m=n-\kappa i: & \text { refractive index of soot } & \Omega: & \text { direction }\end{array}$

$n$ : unit normal vector at wall

\section{Numerical models}

Several advanced numerical models were used for the investigations considering the effects of radiation heat transfer on diesel engine combustion. The CFD code and the numerical models that were used to predict the in-cylinder combustion events are summarized in Table 1. For the prediction of the temperature distribution of the engine components, such as the piston, liner, and cylinder head, a finite element Heat Conduction in Components (HCC) code $^{(5)}$ was used.

Table 1 Summary of numerical code and models.

\begin{tabular}{|c|c|}
\hline Code & KIVA-CHEMKIN-GASJET-DOM \\
\hline Spray model & $\begin{array}{l}\text { KH-RT breakup model } \\
\text { GASJET model }^{(7)}\end{array}$ \\
\hline Radiation & $\begin{array}{l}\text { Discrete Ordinates Method (DOM) } \\
\text { Soot Refractive index } m=n-\kappa i=1.8-1.0 i^{(9)} \\
\text { Hot gas wide-band gray approximation }\end{array}$ \\
\hline Combustion & $\begin{array}{l}\text { Detailed chemistry mechanism }^{(11)} \\
\text { Improved n-heptane reaction mechanism }^{(12)}\end{array}$ \\
\hline Soot formation & Two-step model ${ }^{(11)}$ \\
\hline $\mathrm{NO}_{\mathrm{x}}$ & Improved reduced 19-step model ${ }^{(13)}$ \\
\hline Turbulence & RNG k- $\varepsilon$ \\
\hline Wall temperature & Heat Conduction in Components code ${ }^{(5)}$ \\
\hline
\end{tabular}

The Discrete Ordinates Method (DOM) solves the Radiation Transfer Equation (RTE) for the intensity of radiation in a set of ordinates, each weighted by the solid angle subtended by that ordinate. The RTE and its boundary conditions are $\mathrm{ar}^{(14,8)}$

$$
\begin{aligned}
& (\Omega \cdot \nabla) I(\mathbf{r}, \Omega)=-\left(a+\sigma_{s}\right) I(\mathbf{r}, \Omega)+a I_{b}(\mathbf{r})+\frac{\sigma_{s}}{4 \pi} S(\mathbf{r}, \Omega) \\
& I_{w}(\mathbf{r}, \Omega)=\varepsilon I_{b}(\mathbf{r})+\frac{\rho}{\pi} \int_{\mathbf{n} \cdot \Omega^{\prime}<0}\left|\mathbf{n} \cdot \Omega^{\prime}\right| I\left(\mathbf{n} \cdot \Omega^{\prime}\right) d \Omega^{\prime}
\end{aligned}
$$


where $a$ and $\sigma_{s}$ are the absorption and scattering coefficients of the medium, respectively. The absorption coefficient is computed as a combination of gas absorption $a_{\text {gas }}$ and soot absorption $a_{\text {soot }}$ in this work. $I(\mathbf{r}, \Omega)$ is the radiation intensity, which is a function of position $\mathbf{r}$ and direction $\Omega . I_{b}(\mathbf{r})$ is the intensity of blackbody radiation at the temperature of the medium. $S(\mathbf{r}, \Omega)$ is a source term that accounts for the increase in intensity due to scattering. $I_{w}(\mathbf{r}, \Omega)$ is the radiation intensity leaving a wall, $\varepsilon$ and $\rho=1-\varepsilon$ are the surface emissivity and surface reflectivity, respectively. $\mathbf{n}$ is the unit normal vector at the wall.

Since it is known that soot has a continuous absorptivity spectrum instead of the discrete lines exhibited by gases, the gray body approximation was adopted into the DOM model. Although many researchers have reported that the soot absorption coefficient is a function of the fuel composition (such as the ratio of carbon to hydrogen ${ }^{(15)}$ ), no dependable correlation has been developed. This could also be due to the fact that soot undergoes a metamorphosis in combustion flames as it is formed and oxidized. In this study a method to define the soot absorption coefficient were investigated, that are based on Plank's mean absorption, as suggested by Yuen and Tien ${ }^{(16)}$ :

$$
\varepsilon_{\text {soot }}\left(f_{v} L, T_{\text {soot }}\right)=1-\exp \left(-\frac{3.6 k f_{v} L T_{\text {soot }}}{C_{2}}\right)
$$

where $k$ is a non-dimensional absorption coefficient and $C_{2}$ is the second Plank coefficient. Siegel and Howell proposed a value $k / C_{2}=350 \mathrm{~m}^{-1} \mathrm{~K}^{-1}$ for all types of $\operatorname{soot}^{(10)}$. On the other hand, recent research shows that $k$ for soot should be calculated with a refractive index of $m=n-\kappa i=1.8-1.0 i^{(9)}$ which shows soot absorptivity larger, by about a factor of two, than what many researchers had long believed but which can better estimate the amount of soot in flames and the temperature of these particles. Using the refractive index, the non-dimensional absorption coefficient $k$ can be obtained as ${ }^{(16)}$ :

$$
k=\frac{36 \pi n \kappa}{\left(n^{2}-\kappa^{2}+2\right)^{2}+4 n^{2} \kappa^{2}}
$$

\section{Results and Discussion}

Figure 1 shows comparisons of the measured and predicted in-cylinder gas pressure, Apparent Heat Release Rate (AHRR), and Spatially-Integrated Natural Luminosity (SINL) as a function of crank angle for various SOI timings. SINL is the measured natural luminosity within the field of view through the piston quartz window of the optical research engine by a silicon photodiode. The colored curves are the model predicted results and grayscale curves are experimental results. The predicted results were acquired with the radiation model. The model predicted SINL curves were obtained using a photodiode model $^{(12)}$ which employed the spectral sensitivity, and were normalized according to the peak value of the experimental result of the SOI=-12 CAD ATDC case. The initial in-cylinder temperature was set to have $900 \mathrm{~K}$ as the nominal motored TDC temperature. The surface wall temperatures of the piston surface, cylinder liner, and cylinder head were set to have uniform values, so as to be able to compare with results using distributed wall temperatures later.

The predicted pressure either with or without use of the radiation model agrees well with the experimental data over the entire SOI sweep, from -12 to 15.5 CAD ATDC. From $\mathrm{SOI}=-12$ to $3 \mathrm{CAD}$ ATDC, the model predicted Start of Combustion (SOC) timing and the peak of AHRR in the first stage or premixed combustion regime match the experiments very well. However, the AHRR between the premixed and subsequent diffusion combustion is somewhat over-predicted, so that the model-predicted peak pressures are slightly higher than the experimental results. From $\mathrm{SOI}=8$ to $13 \mathrm{CAD}$ ATDC, the model predicted SOC is 
advanced, and model predicted SOC for SOI=15 and 15.5 CAD ATDC is retarded. The AHRR of the last five SOI cases have lower peaks and longer durations compared with the experimental results, and that leads to the lower pressure rise rate of the predictions. The normalized predicted SINL in the figure from SOI=-12 to 8 CAD ATDC shows similar peak magnitudes to the experimental results, however, the predicted SINL from SOI=10.5 to 15.5 CAD ATDC has higher peak values, while the peak of the experimental SINL drops rapidly.

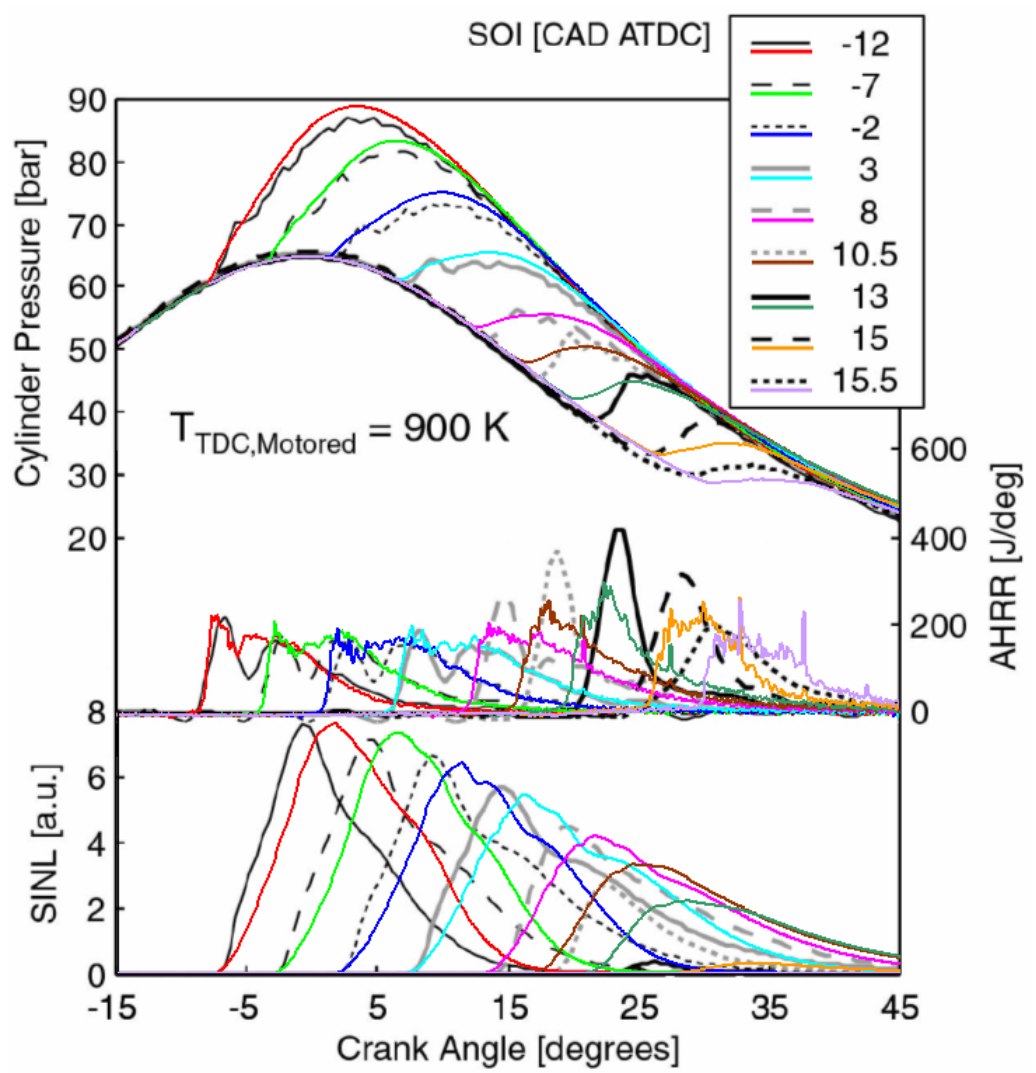

Figure 1 Measured $^{(2)}$ and predicted cylinder pressure, AHRR, and SINL for SOI timing sweep (with radiation, run1) (color, model; gray, experiments).

Figure 2 presents the measured and normalized predicted maximum SINL versus SOI. The predicted peak SINL reduced more gradually as the SOI was retarded. On the other hand, the experimental result has an inflection point at SOI=8 CAD ATDC, then SINL drops suddenly to close to zero.

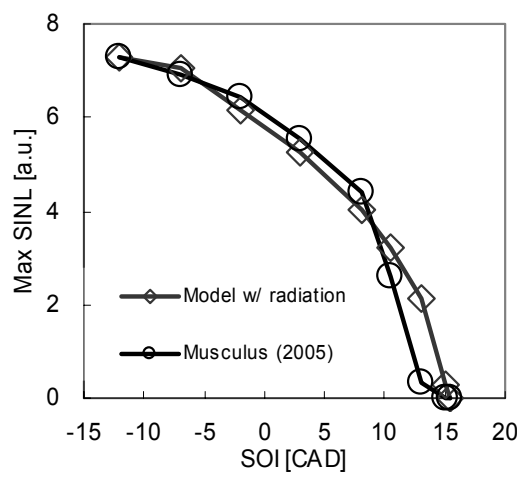

Figure 2 Comparison of measured ${ }^{(2)}$ and normalized model predicted maximum SINL. 
Figure 3 plots the measured and predicted engine-out $\mathrm{NO}_{\mathrm{x}}$ emissions. In Figure 3 (a) an increase of $\mathrm{NO}_{\mathrm{x}}$ emission was observed after $\mathrm{SOI}=8 \mathrm{CAD}$ ATDC, and Musculus ${ }^{(2)}$ referred to this as the "NO${ }_{x}$ bump" due to the elimination of radiation heat loss by soot, which could be associated with the sudden drop of maximum SINL around SOI=8 CAD ATDC. In Figure 3 (b) three results of engine-out $\mathrm{NO}_{\mathrm{x}}$ emissions predicted by the present models are shown. The diamonds are results with radiation, triangles are without radiation, and the crosses are the without soot formation, respectively. The predicted $\mathrm{NO}_{\mathrm{x}}$ amount for all cases is seen to be very much lower than the experimental results but the trend is well captured. In addition, in the predictions an obvious " $\mathrm{NO}_{\mathrm{x}}$ bump" is not observed. However, a reduction in the predicted $\mathrm{NO}_{\mathrm{x}}$ with retard of SOI can be seen around $\mathrm{SOI}=8 \mathrm{CAD}$ ATDC for all prediction cases. With the inclusion of radiation heat loss, the predicted $\mathrm{NO}_{\mathrm{x}}$ emissions were approximately $7.5 \%$ lower than the results without radiation on the average. The result of the prediction without soot formation and radiation was also lower than that without radiation by about $2.5 \%$ on the average. Thus, it can be said that the presence of soot has some influence on the $\mathrm{NO}_{\mathrm{x}}$ formation from a reaction-induced effect; however, the influence was not seen to the extent seen by Guo et al. ${ }^{(1)}$, even for small $\mathrm{NO}_{\mathrm{x}}$ reduction.

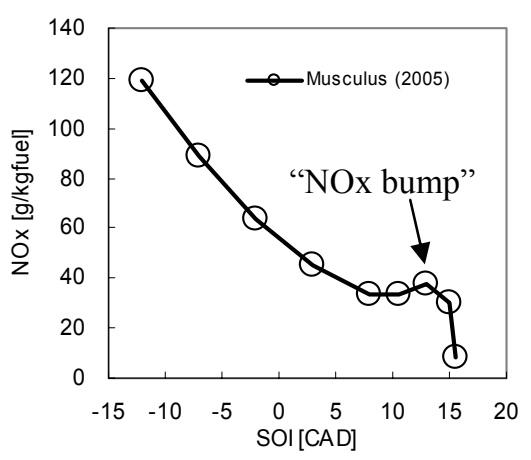

(a) Measured.

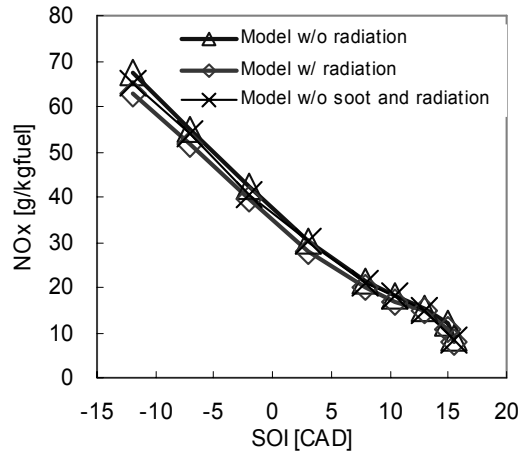

(b) Model predicted.

Figure 3 Comparison of measured and model predicted engine-out $\mathrm{NO}_{\mathrm{x}}$.

Figure 4 presents a plot of the corresponding $\mathrm{NO}_{\mathrm{x}}$ production rate and radiation source term on a $\phi$-T map obtained by the model with radiation for the SOI=-12 CAD ATDC case at $1 \mathrm{CAD}$ ATDC. The horizontal axis is the in-cylinder temperature and the vertical axis is equivalence ratio, $\phi$.

The size of the circles represents the absolute magnitude of the NO production or radiation source term in each computational cell with the dimensions of $\left[\mathrm{M} / \mathrm{L}^{3}\right]$ and $\left[\mathrm{M} /\left(\mathrm{LT}^{2}\right)\right]$, respectively. The solid and white circles in the NO production rate plot in Figure 4 (a) indicate formation and consumption, respectively. The solid and white circles in Figure 4 (b) indicate radiation cooling and heating, respectively. The NO formation rate is seen to increase with elevation of temperature and as the stoichiometric equivalence ratio is approached. In the region of higher equivalence ratio (over 1.2) the NO production rate transitions into NO consumption. The NO consumption has a higher rate in the high temperature region and also in the region closer to the stoichiometric equivalence ratio. On the other hand, the radiation has a cooling effect in computational cells in the NO formation region and in the NO consumption region. Table 2 is a listing of the NO production rate of the model prediction with and without radiation, and the percentage of radiation cooling energy used in the regions of NO formation and consumption. Although there was radiation heating in lower temperature regions, as seen in Figure 4 (b), the total energy of the radiation heating at this crank angle was about $5 \%$ of that of radiation cooling, so that the heating effect was neglected in the table. As seen in Table 2, the radiation effect removes 
almost the same amount of energy from the NO formation region, i.e., $55.9 \%$ of the total cooled energy due to radiation, and in the consumption region, $44.1 \%$. In the NO formation region the formation rate of $\mathrm{NO}$ was reduced by $2 \%$ because of the radiation cooling, while in the NO consumption region the consumption rate of NO was enhanced about $19 \%$ by the radiation cooling, even though the cooled energy was almost the same, as described previously. The results indicate that the reduction of $\mathrm{NO}_{\mathrm{x}}$ emissions due to radiation loss is not by suppressing the $\mathrm{NO}_{\mathrm{x}}$ formation in the flame (which would have high temperatures and stoichiometric equivalence ratios), but mainly by enhancing the $\mathrm{NO}_{\mathrm{x}}$ consumption in the region of relatively high equivalence ratio (i.e., greater than 1.2).

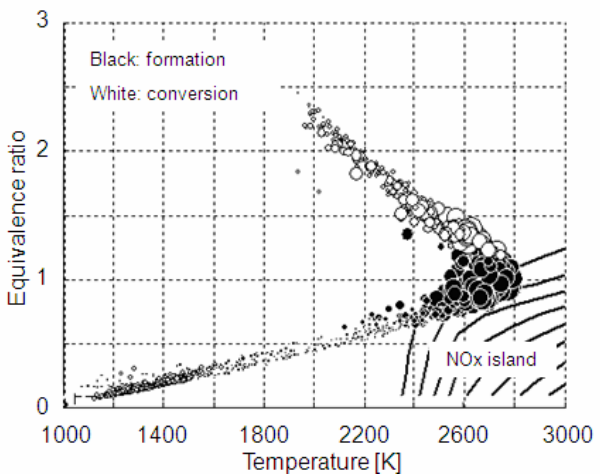

(a) NO production rate in $\left[\mathrm{M} / \mathrm{L}^{3}\right]$.

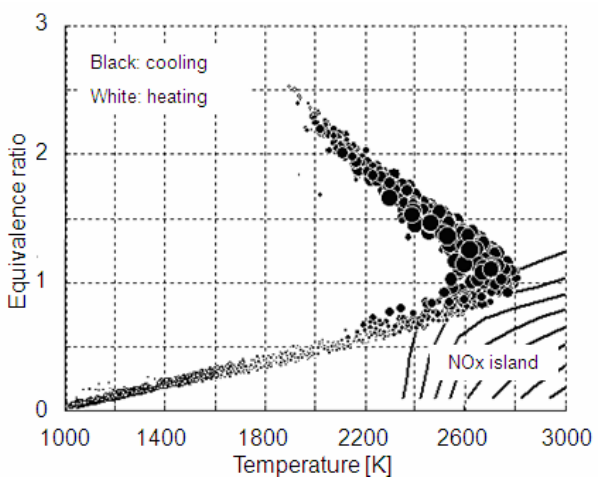

(b) Radiation source term in $\left[\mathrm{M} /\left(\mathrm{LT}^{2}\right)\right]$.

Figure $4 \phi$-T map of model SOI=-12 CAD ATDC case with radiation at 1 CAD ATDC.

Table 2 NO production rate and radiation cooling energy of SOI=-12 CAD ATDC case at 1 CAD ATDC.

\begin{tabular}{|c||c|c|c|}
\hline \multicolumn{1}{|c||}{} & \multicolumn{2}{c|}{ w/ radiation } & w/o radiation \\
\hline $\begin{array}{c}\text { NO } \\
\text { production }\end{array}$ & $\begin{array}{c}\text { Radiation cooling } \\
\text { energy }[\%]\end{array}$ & $\begin{array}{c}\text { Production rate } \\
{[\mathrm{g} / \mathrm{s}]}\end{array}$ & $\begin{array}{c}\text { Production rate } \\
{[\mathrm{g} / \mathrm{s}]}\end{array}$ \\
\hline \hline Formation & 55.9 & 0.428 & 0.437 \\
\hline consumption & 44.1 & -0.187 & -0.157 \\
\hline
\end{tabular}

Model predictions for various fuel spray angles and piston bowl geometries were conducted for low temperature diesel combustion under the same conditions as in the previous section, including three CFD iterations and incorporating the HCC code to set the distributed wall temperature distributions, with and without the radiation model. In this case the CFD-computed heat flux at the combustion chamber walls is used as the wall boundary condition for the HCC code. The HCC-predicted wall temperatures are then used as boundary condition in a second CFD code iteration, and so on. The third CFD results in the iteration were compared with the experimental results. Although a Primary Reference Fuel (PFR) blend of $71 \%$ (by volume) n-heptane and 29\% (by volume) iso-octane, or PFR29, was used in the experiment, $100 \%$ n-heptane chemical reaction kinetics and fuel properties were used in the model prediction due to the availability of a chemistry mechanism ${ }^{(11)}$. Details of the experimental and model prediction cases are given in Refs. (4) and (12).

Figure 5 shows histories of the temperature of the combustion chamber walls for several cases. The number of the cases indicates; No. 1 (baseline case) as spray angle of 152 degree and $70 \%$ bowl geometry to piston bore; No. 2 as 160 degree and $70 \%$ bowl; No. 3 as 124 degree and $70 \%$ bowl; No. 4 as 152 degree and $60 \%$; and No. 5 as 152 degree and $80 \%$ bowl. The temperatures on the cylinder head and the liner (not shown) are fairly steady at the end of the HCC run2 calculation. The surface of the cylinder head does not have much variation of temperature because of the operating condition, while the temperature on the optical engine's quartz piston window has variations of temperature up 
to $33 \mathrm{~K}$. The temperature of case 5 was still increasing even after HCC run2, but the temperatures of all cases reached steady temperatures after more iteration. Note that the engine was operated in skip-fire mode with nine motoring cycles between each fired cycle. This was to prevent the quartz piston from becoming too hot.

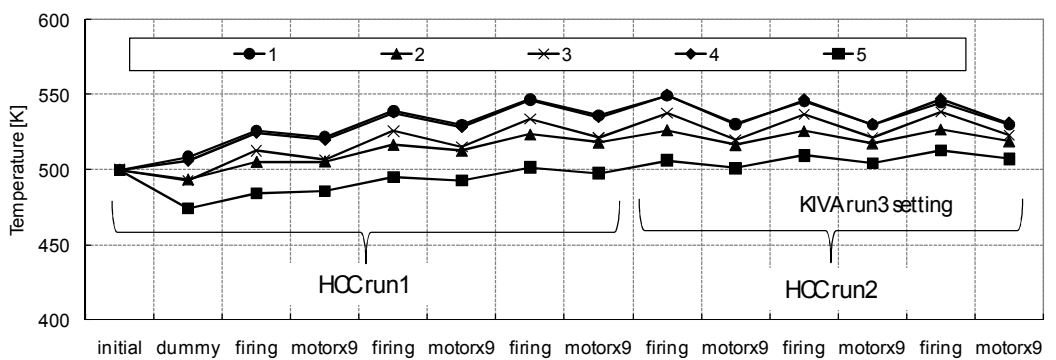

(a) Quartz window.

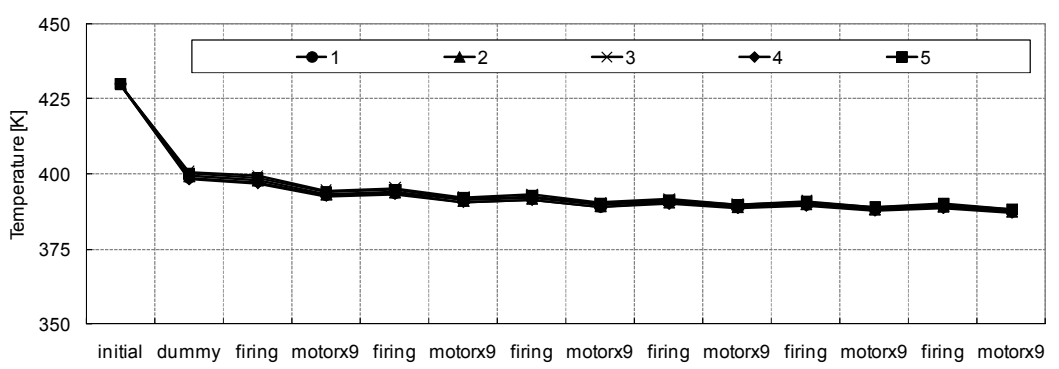

(b) Cylinder head.

Figure 5 Average temperature history of the walls predicted with radiation by HCC.

The effect of the spray angle and radiation heat loss on the emissions and wall temperatures was also investigated. Figure 6 shows the measured and predicted pressure curves for cases 1 (baseline case), 2 and 3, with spray angle 152, 160, and 124 degrees and $70 \%$ piston bowl. Each plot has the results predicted from run1 with radiation, run3 with radiation, and run3 without radiation for comparison. The predicted pressure shows good agreement with the experimental data and run3 results are better than run1. Run3, which considered the wall temperature distribution obtained by the HCC code, showed slightly lower pressure at TDC compared to run1.

The initial average temperatures of the combustion chamber walls are presented in Figure 7. The temperatures were obtained by averaging the distributed temperature over each surface. The temperature of run3 on the cylinder head does not exhibit differences due to the application of the radiation model. It seems that because of the skip-fire operating condition, the heat included that by radiation in the cylinder head which was made of cast iron were removed during nine-time non-firing cycles while heat in the piston quartz window which had lower thermal conductivity remained even after the non-firing cycles. However, the radiation does influence the temperature on the piston surface, quartz window and piston bowl side wall. The increase of temperature on the bowl side wall due to radiation is larger than that on the quartz window. The increase of the wall temperature by radiation heat transfer is about $15 \mathrm{~K}$ on the side wall of the piston bowl and about $5 \mathrm{~K}$ on the quartz window. The temperature on the quartz window after the prediction by the HCC code, viz., the temperature of run3, shows a higher value than the assumed initial temperature for the KIVA run1. On the piston bowl side wall, some predicted temperatures after the iteration are higher, while others have a lower temperature than the run1 initial condition. 

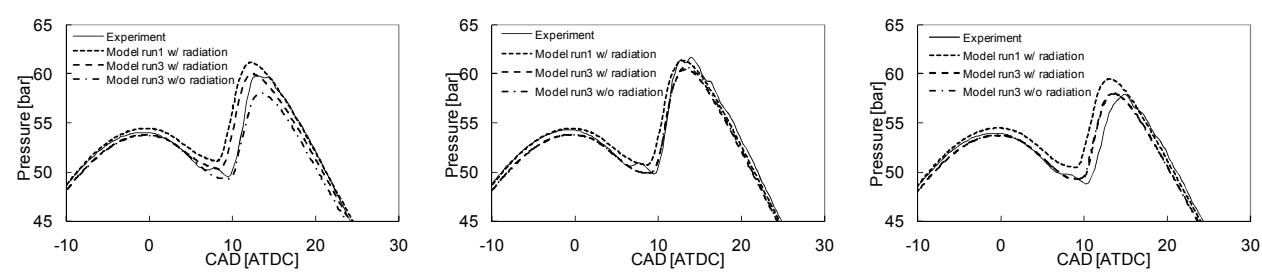

(a) Spray angle $=124$ degree.

(c) Spray angle $=160$ degree.

Figure 6 Measured and predicted pressures when the spray angle is varied (model prediction: KIVA run1 with radiation, run3 with radiation, and run3 without radiation).

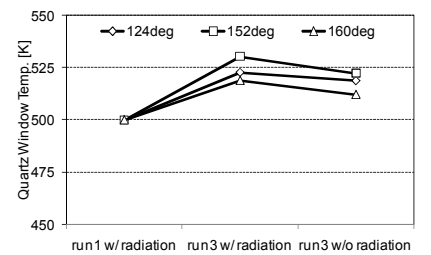

(a) Quartz window.

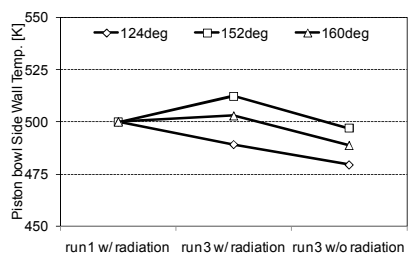

(b) Piston bowl side wall.

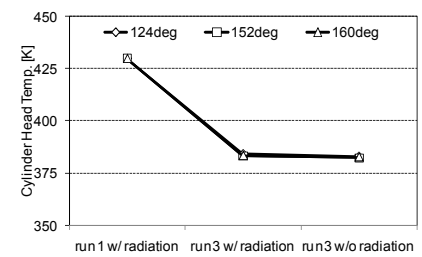

(c) Cylinder head.

Figure 7 Difference of initial average surface temperature for KIVA iteration when varying the spray angle.

Figure 8 shows comparisons of emissions, and convective and radiation heat losses from the combustion chamber walls for run1 and run3, with and without radiation for the various spray angles. By comparing the results with and without radiation for run3, it is seen that application of the radiation model leads to increased soot and decreased $\mathrm{NO}_{\mathrm{x}}$ emissions for all cases, regardless of the spray angle, due to the larger total heat loss of the convective and radiation heat transfer. The influence of the radiation heat loss is significant on the soot emissions, which show up to $13 \%$ differences for the case of spray angle $=124$ degree, while the $\mathrm{NO}_{\mathrm{x}}$ emission change is up to $8.1 \%$, even though the absolute amount of $\mathrm{NO}_{\mathrm{x}}$ is already small. The convective heat loss and the radiation heat loss are almost the same independent of the spray angle, and the ratio of the radiation to the convective heat transfer is less than $10 \%$ for all cases.

By comparing run1 and run3 with radiation, it is seen that the convective heat loss contribution increases during the iteration process. This is because of the larger amount of heat loss from the cylinder head for the run3 case. As seen in Figure 7, almost all surface temperatures of run3 with radiation (except on the cylinder head) are increased; however, the convective heat loss of run 3 is also increased over run1. The increase of the convective heat loss from run1 to run3 leads a decrease of soot and $\mathrm{NO}_{\mathrm{x}}$ emissions of up to $12.2 \%$ and $7.9 \%$, respectively. The variation of engine-out emissions due to the iteration is small for the baseline case which has a 152 degree spray angle. The wide angle case, 160 degree spray angle, has the largest soot reduction rate from run1 to run3. The narrow angle case, 124 degree spray angle, has a different trend in that the iteration process increased the soot emission from run1 to run3.

The difference of the wall temperatures and the application of the radiation model also had little influence on the ignition delay. As seen in Figure 6, the wall temperature distribution change due to radiation affects the in-cylinder pressure at TDC and before ignition. The indirect influence of the wall temperature delays SOC by only up to $1 \mathrm{CAD}$. Application of the radiation model retards SOC for the 124 degree spray angle case, however, there are no differences for the other cases. 


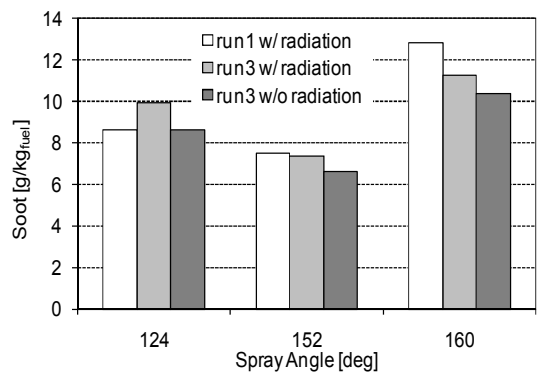

(a) Soot.

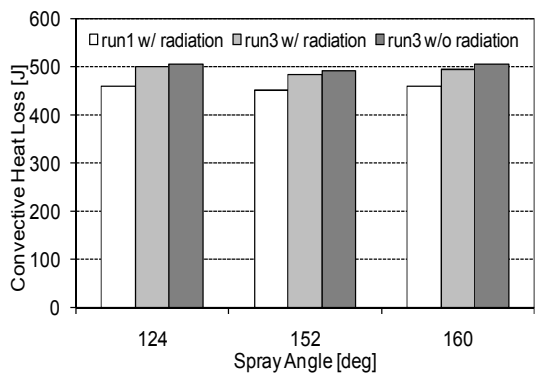

(c) Convective heat loss.

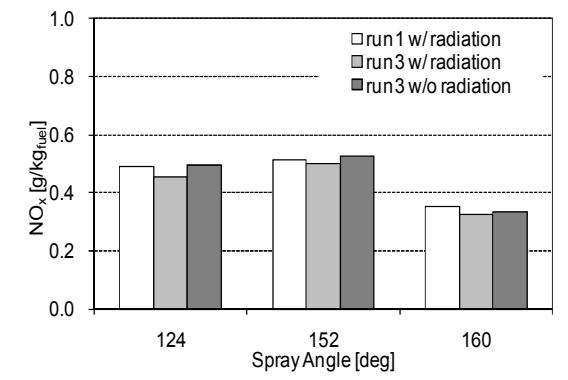

(b) $\mathrm{NO}_{\mathrm{x}}$.

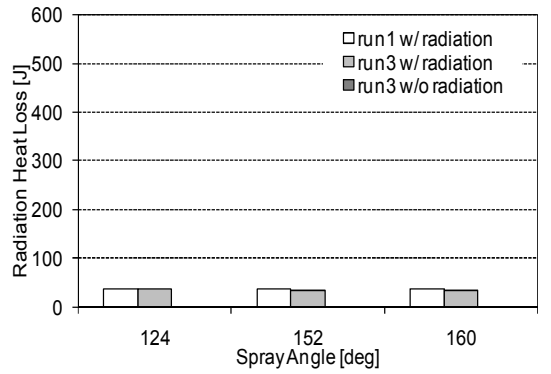

(d) Radiation heat loss.

Figure 8 Comparison of engine-out emissions and heat loss from the walls between run1 and run 3 for various spray angles (152 degree is baseline case, 70\% bowl diameter for all cases).

The effect of piston bowl geometry and radiation heat losses on the emissions and wall temperatures was also investigated. Figure 9 shows the measured and model predicted pressures for cases 1 (baseline case), 4, and 5, with piston bowl diameter 70, 60, and $80 \%$ of the bore whose spray angles are 152, 140, and 160 degrees and target the middle height of the piston bowl side wall. Each plot has predictions by KIVA run1 with radiation model, KIVA run3 with radiation model, and KIVA run3 without radiation model for comparison. The predicted pressure agrees with the experimental data and run3 shows improved results over run1, as was found also for the spray angle variation cases. Run3 of the model prediction which considered the wall temperature distribution obtained by the HCC code showed slightly lower pressure at TDC compared to run1.

The initial average temperatures of the combustion chamber walls are presented in Figure 10. The temperature of the $60 \%$ piston bowl case is identical with that of the $70 \%$ piston bowl case while the $80 \%$ piston bowl case has $30 \mathrm{~K}$ lower temperature than those on the quartz window and piston bowl side wall surfaces. The increase of the wall temperature by radiation heat transfer is about $10 \mathrm{~K}$ on the side wall of the piston bowl and about $7 \mathrm{~K}$ on the quartz window. The temperature on the quartz window after the prediction by the HCC code, viz., the temperature of run3 is higher than the initial assumed temperature for KIVA run 1 for the 60 and $70 \%$ piston bowls. The surface temperature of the $80 \%$ piston bowl case is always lower than the initial temperature for KIVA run1

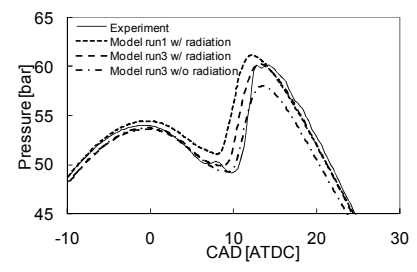

(a) $60 \%$ piston bowl.

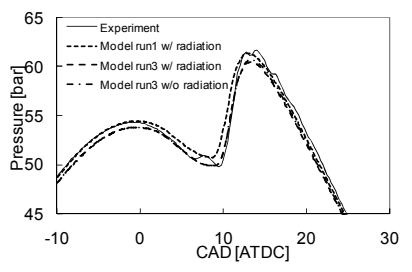

(b) $70 \%$ piston bowl.

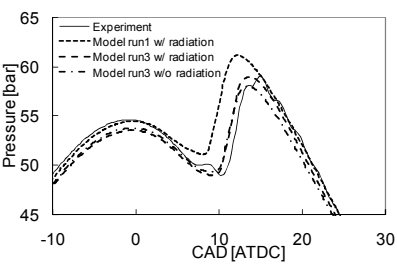

(c) $80 \%$ piston bowl.

Figure 9 Measured and predicted pressures when the piston bowl geometry is varied (model prediction: KIVA run1 with radiation, run3 with radiation, and run3 without radiation). 


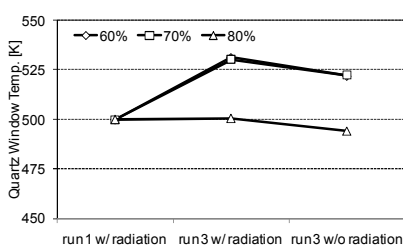

(a) Quartz window.

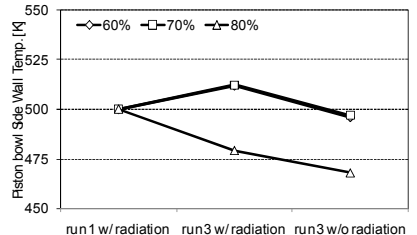

(b) Piston bowl side wall.

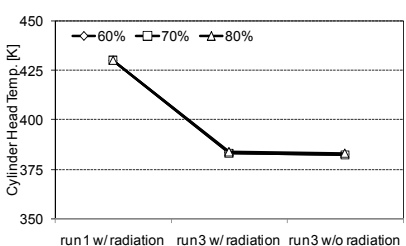

(c) Cylinder head.

Figure 10 Difference of initial average surface temperature for KIVA iteration when varying the bowl geometry.

Figure 11 compares emissions, and convective and radiation heat losses from the combustion chamber walls for run1 and run3, with and without radiation for the various piston bowl geometries. It is seen that application of the radiation model increases soot and decreases $\mathrm{NO}_{\mathrm{x}}$ emissions for all cases, regardless of the bowl geometry, due to the larger total heat loss of the convective and radiation heat transfer. The trend is the same as that seen by varying the spray angle investigated previously. The influence of the radiation heat loss on the soot emissions leads to a $10.4 \%$ difference from the baseline $70 \%$ piston bowl case, while the $\mathrm{NO}_{\mathrm{x}}$ emissions change by up to $4.6 \%$ (however, the absolute amount of $\mathrm{NO}_{\mathrm{x}}$ is already small). Radiation effects on emissions for the various piston bowl geometries are smaller than the effects of varying the spray angle. The convective and radiation heat losses are almost same for each piston geometry and the ratio of the radiation to the convective heat transfer is less than $10 \%$ for all cases.

It is seen that the convective heat loss increases after the iteration process as was seen for the various spray angle cases. The increase of the convective heat loss from run 1 to run 3 leads to a decrease of soot and $\mathrm{NO}_{\mathrm{x}}$ emissions by up to $15.9 \%$ and $8.6 \%$, respectively.

The variation of the emissions over the different piston bowl geometries is smaller than that by varying the spray angle. Radiation retards SOC more for the $60 \%$ piston geometry case, as seen in Figure 9, but not significantly for the other cases.

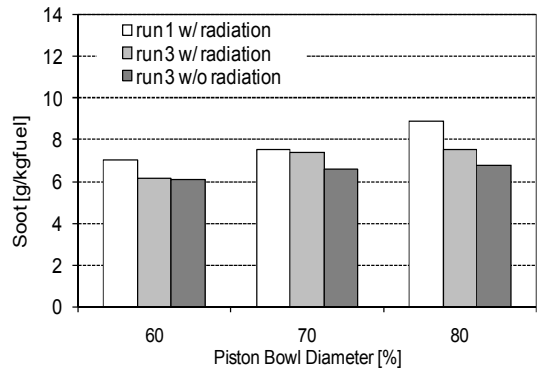

(a) Soot.

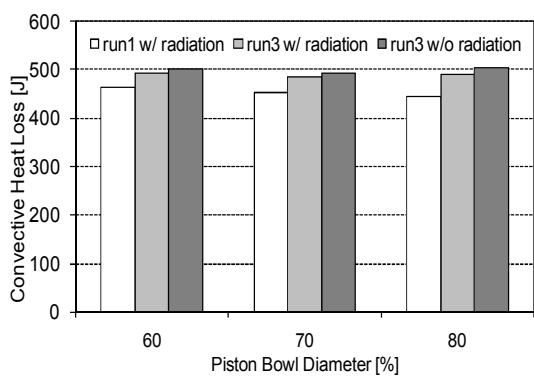

(c) Convective heat loss.

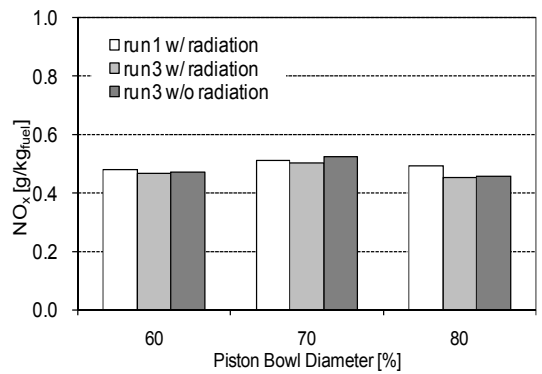

(b) $\mathrm{NO}_{\mathrm{x}}$.

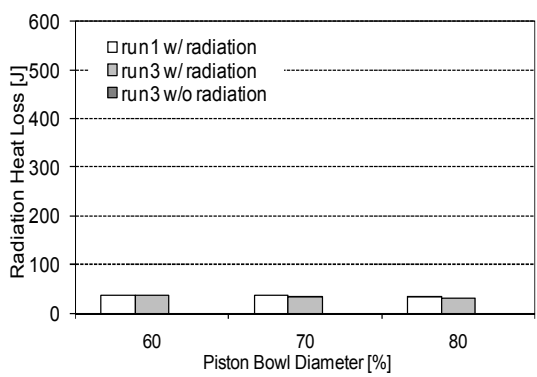

(d) Radiation heat loss.

Figure 11 Comparison of engine-out emissions and heat loss from the walls between run1 and run3 for various bowl geometries ( $70 \%$ bowl diameter is baseline case). 
As shown in Figure 2, the model predicted soot was compared with measured soot using normalized SINL but not the amount or concentration of it. The model predicted soot amount can be over- or under-predicted compared to the actual amount of soot in the cylinder which was not measured at this time unfortunately. If the amount of soot is over-predicted in the model, SINL and radiation heat loss to the wall can be over-predicted, and the model predicted $\mathrm{NO}_{\mathrm{x}}$ can be under-predicted. On the other hand, if the amount of soot is under-predicted in the model, SINL and radiation heat loss to the wall can be under-predicted, and the model predicted $\mathrm{NO}_{\mathrm{x}}$ can be over-predicted.

\section{Summary and Conclusions}

The interaction between soot and $\mathrm{NO}_{\mathrm{x}}$ emissions was studied for low temperature diesel combustion to further understand the phenomenon where a decrease of combustion luminosity, i.e., soot radiation, increases $\mathrm{NO}_{\mathrm{x}}$ emission for retarded $\mathrm{SOI}$ cases ${ }^{(2)}$. Also, the influence of the spray angle and piston bowl geometry on soot radiation and wall temperatures was examined by comparing with experimental results from an optical engine. For improved wall temperature prediction accuracy, the model predictions employed three CFD code iterations with a finite element heat conduction code (HCC). The following results were found:

1. The model predicted in-cylinder pressure and AHRR curves agreed well with the experiments for all cases.

2. A reduction in predicted $\mathrm{NO}_{\mathrm{x}}$ with retard of $\mathrm{SOI}$ was seen around $\mathrm{SOI}=8 \mathrm{CAD}$ ATDC, as in the experiments. With radiation heat loss, the predicted $\mathrm{NO}_{\mathrm{x}}$ emissions were approximately $7.5 \%$ lower than without radiation. $\mathrm{NO}_{\mathrm{x}}$ without soot formation and radiation was lower than without radiation by about $2.5 \%$. Thus, the presence of soot has some influence on $\mathrm{NO}_{\mathrm{x}}$ formation; however, the influence was small.

3. The results indicate that the reduction of $\mathrm{NO}_{\mathrm{x}}$ emissions due to radiation heat loss is not by suppressing the $\mathrm{NO}_{\mathrm{x}}$ formation in the flame (which would have high temperatures and stoichiometric equivalence ratios), but mainly occurs by enhancing the $\mathrm{NO}_{\mathrm{x}}$ consumption in regions of relatively high equivalence ratio (i.e., greater than 1.2).

4. The predicted $\mathrm{NO}_{\mathrm{x}}$ emissions for the various spray angle cases were reduced by up to $8.1 \%$ with radiation, while the soot emissions increased up to $13 \%$. The influence of radiation was larger on soot than on $\mathrm{NO}_{\mathrm{x}}$ emissions. The influence of wall temperatures, or heat loss from the wall, was significant to soot emissions, and the resulting decreased temperature of the cylinder head and liner decreased soot emissions by $12.2 \%$.

5. $\mathrm{NO}_{\mathrm{x}}$ emissions for the various piston bowl diameter were reduced up to $4.6 \%$ with radiation, while the soot emissions increased up to $10.4 \%$. The influence of radiation was larger on soot than on $\mathrm{NO}_{\mathrm{x}}$ emissions as well. The influence of wall temperatures, or heat loss from the wall, was significant to soot emissions, and the corresponding decreased temperature of the cylinder head and liner decreased soot emission by $15.9 \%$. From the model predictions the variation of engine-out emissions due to the various piston bowl geometries was smaller than that due to differences in the spray angle.

\section{Acknowledgement}

Sincere appreciation is due to the Department of Energy and the Sandia National Laboratory for support and for providing valuable optical engine experimental data. Also, thanks are due to the Technical Research and Development Institute, Japan Ministry of Defense, for their financial support and for the opportunity to study abroad in the United 
States of America in a doctoral program.

\section{References}

(1) Guo, H., and Smallwood, G. J., "The interaction between soot and NO formation in a laminar axisymmetric coflow ethylene/air diffusion flame," Combustion and Flame, 149, pp. 225-233, 2007.

(2) Musculus, M. P. B., "Measurements of the Influence of Soot Radiation on In-Cylinder Temperatures and Exhaust $\mathrm{NO}_{\mathrm{x}}$ in a Heavy-Duty DI Diesel Engine," SAE Paper No. 2005-01-0925, 2005.

(3) Abraham, J., and Magi, V., "Application of the Discrete Ordinates Method to Compute Radiant Heat Loss in a Diesel Engine," Numerical Heat Transfer, Part A, Vol. 31, pp. 597-610, 1997.

(4) Genzale, C. L., Reitz, R. D., Musculus, M. P. B., "Effects of Piston Bowl Geometry on Mixture Development and Late-Injection Low-Temperature Combustion in a Heavy-Duty Diesel Engine," SAE Technical paper No. 2008-01-1330, 2008.

(5) Wiedenhoefer, J. F. and Reitz, R. D., "Modeling the Effect of EGR and Multiple Injection Schemes on I. C. Engine Component Temperatures," Numerical Heat Transfer, Part A, Vol. 37, pp. 673-694, 2000.

(6) Patterson, M. A. and Reitz, R.D., "Modeling the Effeects of Fuel Spray Charecteristics on Diesel Engine Combustion and Emissions," SAE Technical paper No. 980131, 1998.

(7) Abani, N., Munnannur, A., and Reitz, R. D., "Reduction of Numerical Parameter Dependencies in Diesel Spray Models," Journal of Engineering for Gas Turbines and Power (Vol. 130, Iss. 3): URL:http://link.aip.org/link/?GTP/130/032809, DOI: 10.1115/1.2830867, 2008.

(8) Wiedenhoefer, J.F.; Reitz, R.D., "A Multidimensional Radiation Model for Diesel Engine Simulations with Comparison to Experiment," Numerical Heat Transfer: International Journal of Computation and Methodology Part A: Applications, 44 (7): 665-682 November issue, 2003.

(9) Shaddix, C. R., Williams, T. C., "Soot: Giver and Taker of Light," American Scientist, Vol. 95, pp. 232-239, 2007.

(10) Siegel, R., Howell, J. R., Thermal Radiation Heat Transfer, Third Edition, Taylor \& Francis, Washington, 1992.

(11) Kong, S. C., Sun, Y., and Reitz, R. D., "Modeling Diesel Spray Flame Liftoff, Sooting Tendency, and $\mathrm{NO}_{\mathrm{x}}$ Emissions Using Detailed Chemistry With Phenomenological Soot Model," Journal of Engineering for Gas Turbines and Power, Vol. 129, pp. 245-251, 2007.

(12) Yoshikawa, T., "Effect of Radiation on Diesel Engine Combustion and Heat Transfer," Ph.D Thesis, University of Wisconsin-Madison, 2008.

(13) Yoshikawa, T., and Reitz, R.D., "Development of an Improved NOx Reaction mechanism for Low Temperature Diesel Combustion Modeling," SAE Paper 2008-01-2413, 2008.

(14) Fiveland, W. A., "Three-Dimensional Radiative Heat Transfer Solutions by the Discrete-Ordinates Method," Journal of Thermophysics and Heat Transfer, Vol. 2, No. 4, pp. 309-316, 1988.

(15) Modest, M. F., Radiative Heat Transfer, McGraw-Hill, New York, 1993.

(16) Yuen, W. W., Tien, C. L., "A simple calculation scheme for the luminous-flame emissivity," Sixteenth Symp. (Int.) Combust., The Combustion Institute, pp. 1481-1487, 1977. 